\title{
Surgical Treatment of Supra- and Infratentorial Epidural Hematoma
}

\author{
Supra- ve Infratentorial Epidural Hematomun Cerrahi Tedavisi
}

\author{
Wang XIAOYU, Li GUOPING \\ Sichuan University, Department of Neurosurgery, Chengdu, China
}

Corresponding Author: Li GUOPING / E-mail: yuxixi1052006@126.com

\begin{abstract}
Supra- and infratentorial acute epidural hematoma (SIEDH) is a common type of posterior fossa epidural hematoma (PFEDH), representing 11$64 \%$ of all PFEDHs. Although SIEDH is associated with typical characteristics, it might be difficult to diagnose when presenting as infratentorial acute epidural hematoma, which is clinically silent and has nonspecific symptoms. However, this type of hematoma can often be rapidly deteriorating, causing a sharp rise in intracranial pressure that leads to a life-threatening foramen magnum herniation. Early diagnosis and management of SIEDH are imperative. Traditional surgical management has always required relatively large craniotomies, larger than the hematoma itself, to expose its edge, and then tack up the dura matter). It usually opens the window and emphasizes retention of the bone bridge outside the transverse sinus. This method can effectively eliminate the hematoma, but it is associated with larger postoperative wound, longer operation time, larger skull defect, and more complications. Hence, exploration into a better surgical method is direly needed.
\end{abstract}

KEYWORDS: Acute epidural haematoma, Craniectomy, Posterior fossa, Cleaning hematoma

\section{öz}

Supra- ve infratentorial akut epidural hematom (SIEDH) sık görülen bir posterior fossa epidural hematomu (PFEDH), tipidir ve tüm PEEDS'lerin \% 11-64'ünü temsil eder. SIEDH'nin tipik özellikleri olsa da klinik olarak sessiz olan ve belirtileri nonspesifik olan bir infratentoriyal akut epidural hematom olarak ortaya çıktığında tanı konması zor olabilir. Ancak bu tür hematom hızla kötüye gidebilir ve yaşamı tehdit edici foramen magnum herniasyonuna yol açacak şekilde intrakraniyal basınçta ani bir yükselişe neden olabilir. SIEDH için erken tanı ve tedavi şarttır. Geleneksel cerrahi tedavi hematomun kenarını göstermek ve sonra dura materi kapatmak için hematomun kendisinden daha büyük nispeten büyük granülotomiler gerektirmiştir. Sıklıkla transvers sinüs dışındaki kemik köprünün retansiyonunu vurgular ve pencereyi açar. Bu yöntem hematomu etkin şekilde ortadan kaldırabilir ama daha büyük bir postoperatif yara, daha uzun ameliyat süresi, daha büyük kafatası defekti ve daha fazla komplikasyonla ilişkilidir. Bu nedenle, daha iyi bir cerrahi yöntemin bulunması kesin olarak gereklidir.

ANAHTAR SÖZCÜKLER: Akut epidural hematom, Kraniyektomi, Posterior fossa, Hematom temizleme

\section{INTRODUCTION}

Supra- and infratentorial acute epidural hematoma (SIEDH) is a common type of posterior fossa epidural hematoma (PFEDH), representing $11-64 \%$ of all PFEDHs $(1,3-6,10-12,14$, 17). Although SIEDH is associated with typical characteristics, it might be difficult to diagnose when presenting as infratentorial acute epidural hematoma, which is clinically silent and has nonspecific symptoms (2). However, this type of hematoma can often be rapidly deteriorating, causing a sharp rise in intracranial pressure that leads to a lifethreatening foramen magnum herniation. Early diagnosis and management of SIEDH are imperative (7-9). Traditional surgical management has always required relatively large craniotomies, larger than the hematoma itself, to expose its edge, and then tack up the dura matter (15-16). It usually opens the window and emphasizes retention of the bone bridge outside the transverse sinus. This method can effectively eliminate the hematoma, but it is associated with larger postoperative wound, longer operation time, larger skull defect, and more complications. Hence, exploration into a better surgical method is direly needed.

In this article, we adopted the supratentorial approach in 25 patients with SIEDH, who were diagnosed and treated at the Department of Neurosurgery, West China Hospital, Sichuan University, Sichuan, China, between January 2006 and August 2009. We conducted a retrospective study of patient records to evaluate the technical aspects of the supratentorial approach with respect to the surgical indications, treatment effects, limitations, and complications. This evaluation suggests that the supratentorial approach provides good results in patients with SIEDH. It is the first report to describe the supratentorial approach for the management of SIEDH.

\section{MATERIAL and METHODS}

\section{Patient Population}

25 patients with SIEDH were evaluated and surgically treated at the Department of Neurosurgery, West China Hospital, 
between January 2006 and August 2009. There were 15 men and 10 women, with the mean age of 18.2 years (range, 4-52 years). The hematomas were traumatic in all cases; the cause was traffic accidents in 23 patients, a tumble in 1, and a fall from a high area in 1 . All patients were struck in the occipital region. The interval between injury and admission to our hospital ranged from 2-24 hours (mean, 8 hours).

\section{Evaluation}

From a total number of 54 patients with PFEDH, 25 patients were diagnosed with SIEDH by CT (46.3\% of PFEDH cases). The clinical course of traumatic PFEDH was classified as acute, subacute, and chronic, with the onset of symptoms within the first 24 hours of trauma, until the 7th day post-trauma, and thereafter, respectively (3). The Glasgow Coma Scale (GCS) was used to assess the level of consciousness in the surviving patients (13). Surgical indications, determined by CT findings, are: 1) obliteration of the perimesencephalic cisterns (particularly the quadrigeminal cistern); 2) compression and/ or displacement of the fourth ventricle, and the presence of hydrocephalus; 3 ) extension of the hematoma to the supratentorial region, with marked compression to the brain.

\section{Technique}

25 patients were intubated under general anesthesia during surgery. The patients were in a lateral or prone position, with the head secured in a Mayfield head holder. Anatomic landmarks (e.g., midline, the transverse sinus) were marked with a skin marker. According to the size and location of supratentorial hematoma, the site of the craniotomy was marked on the skin. For 23 patients with unilateral hematoma, which did not extend to the midline, a unilateral occipital skin flap was incised. For 2 patients with bilateral hematoma, which extended to the midline, the skin flap crossed the midline depending on the location of hematoma. The incised skin flap was turned toward the neck. Four burr holes in the four corners of bone flap were drilled with a highspeed bone drill. The bone flap was cut off by using a highspeed craniotome. For bone flaps that crossed the midline, a high-speed craniotome was used without sinus injury if the hematoma was thick. But when the hematomas were thin, 2 burr holes were drilled on both sides of midline and then a rongeur was used to open the bone to avoid sinus injury. The bone flap was then removed and parts of hematoma were explored. The supratentorial hematoma was cleaned and the dura was slinged, except toward the transverse sinus. In sinus region, the hematoma was cleaned near the bone first, preventing dissection of the hematoma by force. Then the infratentorial hematoma was cleaned. If a meningeal hemorrhage was observed, a bipolar was used to stop the hemorrhage. If sinus bleeding was encountered, compression with a gelfoam was applied and the dura was secured with tack-up stitches. Most of hematomas were passively removed by this method. Finally, an epidural catheter drainage tube with a silicone vacuum was insered, the bone was reset, and the scalp was sutured (Figure 1A-F).

\section{RESULTS}

\section{Clinical Presentation}

The time interval from injury to diagnosis ranged from 2 to 24 hours; 22 of the patients were diagnosed within 24 hours (acute SIEDH) and 3 within 7 days (subacute SIEDH). No patients diagnosed beyond 7 days were encountered (chronic cases). Acute cases were of all ages, with a peak incidence in those aged $16-20$ years.

The most important complications were occipital swelling (25 patients), headache (24 patients), and vomiting (12 patients). The symptoms and signs of the patients are summarized in Table I. Admission GCS score was 3-8 points in 2 patients, 9-12 points in 4 patients, and $13-15$ points and 19 patients. Papilledema was observed in 8 patients.

\section{Radiological Findings}

23 patients had unilateral SIEDH, of which 10 were on the left and 13 on the right. In 2 patients, the hematoma was bilateral. 21 patients had fracture of the occipital bone as revealed by CT bone window level films.18 patients had fourth ventricle compression and 3 patients had hydrocephalus. The first examination revealed a hematoma in 23 patients and a late fat hematoma in 2 patients. Tada epidural hematoma volume was $10-25 \mathrm{~mL}$ (mean, $17 \mathrm{~mL}$ ).

\section{Associated Lesions}

We observed an acute temporoparietal epidural hematoma in 2 patients, a frontal hemorrhagic contusion in 3 patients, a pneumocephalus in 4 patients, and basal skull fractures with cerebrospinal (CSF) fistula in 2 patients (Table II).

\section{Surgical Management}

A total of 25 patients with SIEDH were surgically treated by the supratentorial approach. Intraoperative linear fracture of the occipital region was observed in 21 patients, and bleeding from the transverse sinus was observed in 3 patients. The fracture line at the plate barrier with bleeding was observed in 18 patients, meningeal blood vessel bleeding in 4 patients, and no active bleeding point in 25 patients (Table III). Blood loss during the operation ranged from $30-60 \mathrm{~mL}$, with mean blood loss of $40 \mathrm{~mL}$. Operation time ranged from 45-120 min (mean, 55 min). Hematoma was not visible on CT scan on the day after the first surgical operation, with no further intracranial bleeding (Figure 2). GCS score revealed that 23 patients recovered well; 2 patients who had GCS score of 3-8 on admission were moderately disabled following discharge from hospital.

\section{DISCUSSION}

SIEDH is a common type of posterior fossa epidural hematoma (PFEDH), representing 11-64\% of all PFEDHs (1, 3-6, 10-12, $14,17)$. In our series, 25 patients were diagnosed with SIEDH, accounting for $46.3 \%$ of the total of 54 patients with PFEDH. The entity was a lesion of younger-aged patients, mainly in those aged 16-20 years, with mean age of 17 years. This 


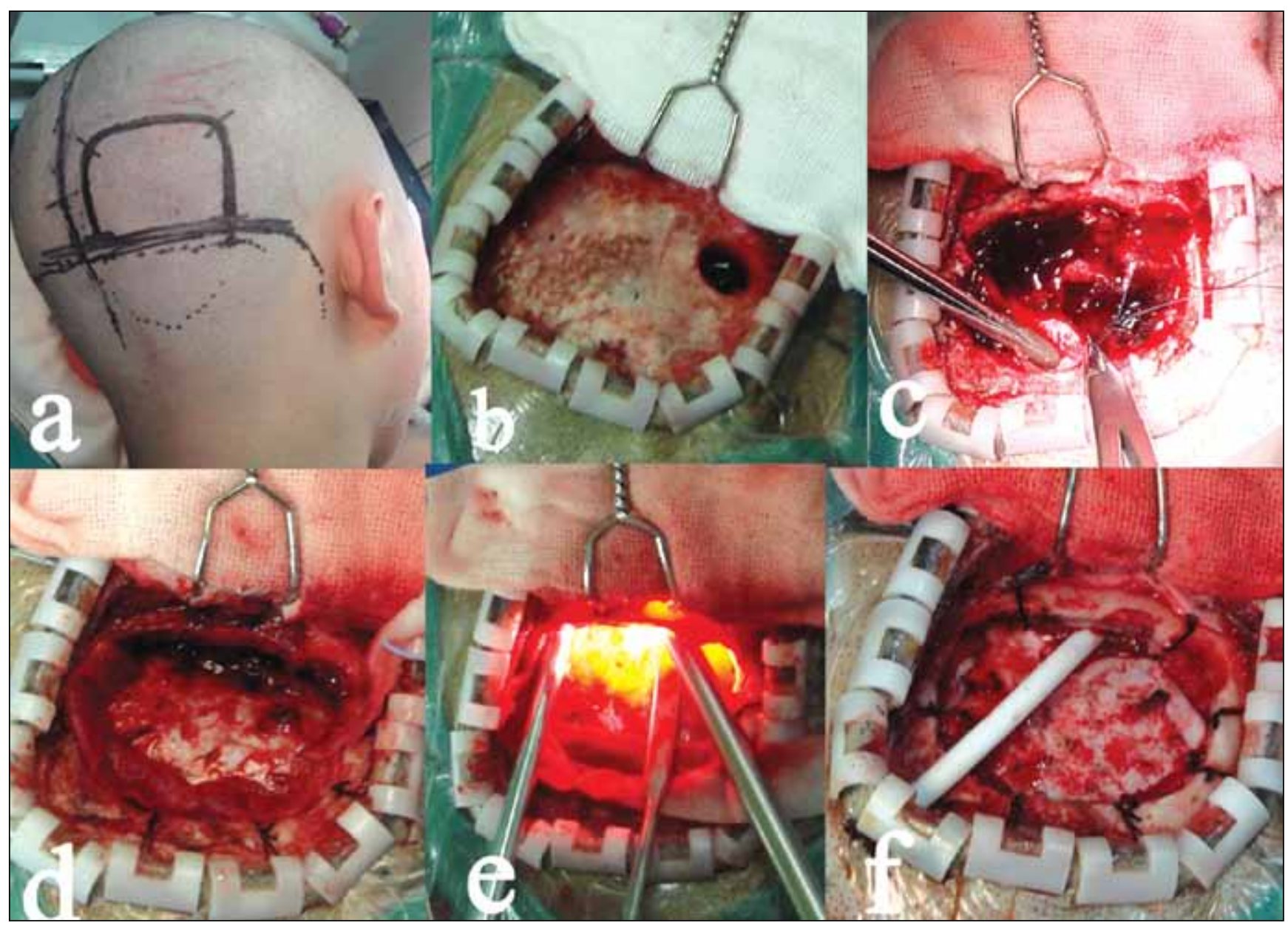

Figure 1: Photographs of the operative procedure. A) Planned skin incision with a skin marker of the midline and transverse sinus. B) Incised skin flap was turned toward the neck, making a burr hole in bone flap. C) Exposure of the hematoma and slinging of the dura. D) Supratentorial hematoma was cleaned. E) Infratentorial hematoma was cleaned. F) An epidural catheter drainage tube with a silicone vacuum was inserted and the dura was slinged.

Table I: Signs and Symptoms

\begin{tabular}{|l|c|c|}
\hline Signs and symptoms & $\begin{array}{c}\text { No. of } \\
\text { signs }\end{array}$ & $\begin{array}{c}\text { Percentage } \\
\text { of signs(\%) }\end{array}$ \\
\hline Occipital swelling & 25 & 100 \\
\hline Headache & 22 & 88 \\
\hline Vomiting & 16 & 64 \\
\hline Cerebellar signs and symptoms & 4 & 16 \\
\hline Pyramidal signs & 3 & 12 \\
\hline Loss of consciousness & 2 & 8 \\
\hline Anisocoria & 1 & 4 \\
\hline Otorrhagia & 8 & 32 \\
\hline Occipital fracture & 23 & 92 \\
\hline
\end{tabular}

Table II: Associated Lessions

\begin{tabular}{l|c|}
\hline Associated lessons & No. of cases \\
\hline Temporoparietal epidural hematomas & 2 \\
\hline Frontal hemorrhagic contusion & 3 \\
\hline Pneumocephalus & 2 \\
\hline Basal skull fractures with & 4 \\
\hline Cerebrospinal (csf) fistula & \\
& \\
Table III: Bleeding Point & \\
\hline Bleeding from & No. of cases \\
\hline Transverse sinus & 3 \\
\hline The fracture line at the plate barrier & 18 \\
\hline Meningeal blood vessels bleeding & 4
\end{tabular}




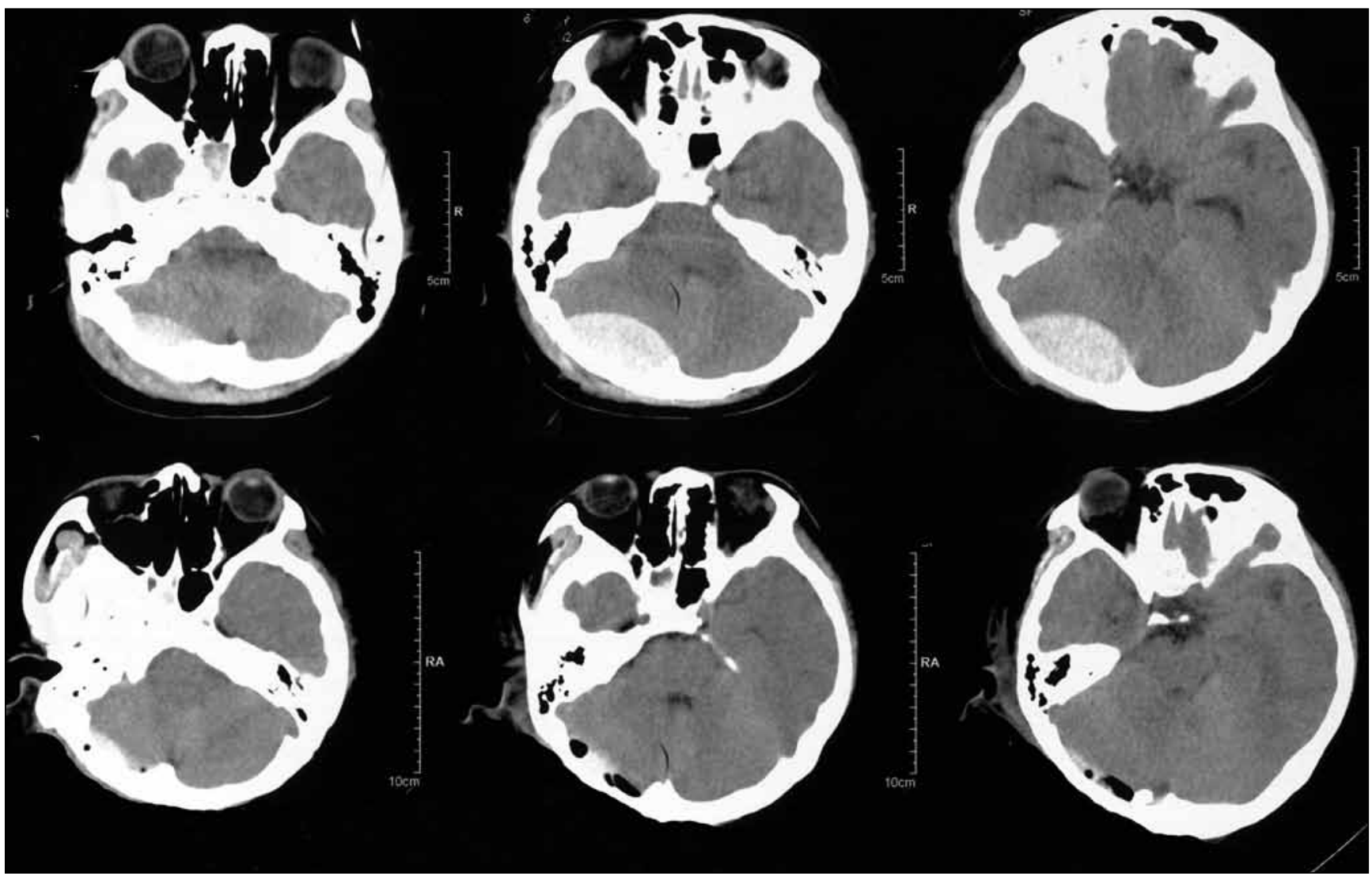

Figure 2: Right supra- and infratentorial acute epidural hematoma was not visible on CT scan on the day after the first surgical operation, with no further intracranial bleeding.

differs from previously reported findings, and our results may be related to the means of transporting our youth to hospital.

The patients had a history of occipital trauma, headache, vomiting, unconsciousness, neck resistance, mastoid region ecchymosis (Battle's sign), and diagnosis of SIEDH was confirmed by CT inspection. The main clinical manifestations of SIEDH are headache, vomiting, neck resistance, and lack of the typical signs of nervous system orientation. The condition may rapidly deteriorate, causing compression of the transverse sinus and brain stem and subsequently death of the patient (1-9). This type of epidural hematoma mainly occurs due to occipital deceleration injury, most often associated with occipital bone fracture or lambdoid suture separation (3-4). Venous sinus detachment, meningeal blood vessels leakage, and a fracture line across the transverse sinus all lead to SIDEH (3). We did not find sinus tear in our 25 patients, as the bone of the sinus region was extremely thick and difficult to tear.

The transverse sinus collects blood from the superior sagittal sinus, straight sinus, great cerebral vein, cerebral vein, and other blood vessels, but its sinus pressure is $50 \%$ smaller than other sinus (3-4). If the transverse sinus is compressed, causing venous return disorder, the symptoms of intracranial hypertension can be significant and can rapidly form tonsillar herniation, which is difficult to resolve, even with strong dehydration and hormone treatment. Therefore, once SIEDH is confirmed, surgery should be performed as soon as possible to eliminate the hematoma and lift the compression to the transverse sinus.

Traditional surgical management of SIEDH has always required relatively large craniotomies, sometimes even larger than the hematoma itself, to expose its edges and the bleeding. So it is always necessary to combine suboccipital craniectomy with the supratentorial approach to achieve complete hematoma evacuation. However, this leads to bigger postoperative wound and requires dissection of the muscle of cervicooccipital region, causing more blood loss and longer operation time (almost 2-3hours longer) as well as more financial costs. In hospitals where there is no a high-speed bone drill and craniotome, suboccipital craniectomy is hard to perform and always leads to bone defects. Bone defects not only lead to cosmetic problems, but also functional deficits. An occipital bone defect may require another surgery of cranioplasty. This type of bone defect may cause psychological problems, particularly in children, affecting cognitive development. Thus, bone flap replacement is consistent with anatomical concerns as well as neurological recovery. The packing around the transverse sinus may compress the sinus and obstruct the blood flow. The bone defect after traditional suboccipital craniectomy may result in complications of subcutaneous hydrops and CSF leakage, which may lead to postoperative 
wound infection and intracranial infection. Another operation might be needed to solve those problems, extending the hospitalization stay of the patients and increasing the financial burden on the health system. Therefore, traditional suboccipital craniectomy should be reduced to a minimum in the management of patients with SIEDH.

As there are no major meningeal arteries and main branch vessels in the posterial fossa, no sinus tearing is encountered with the supratentorial approach, facilitating hemostasis. Also, detachment of the transverse sinus and dura, caused by hematoma, can lead to formation of a compartment with bone, which allows for the removal of the infratentorial part. We can thus use the supratentorial approach to remove all parts of SIEDH throughout that compartment.

Dissection of the hematoma by force is intraoperatively contraindicated in the sinus region. If bleeding is encountered, the recommendation is to compress it with gelfoam and secure it with tack-up stitches. From our experience, suction can be used to suck out the residual hematoma as long as one is close to the edge of the hematoma.

The improved method has following advantages: bone resetting meets the requirements of anatomy and prevents skull defects, which are caused by the conventional methods; complete removal of the hematoma, effectively lifting transverse sinus compression and avoiding excessive suspension of the transverse sinus that causes venous reflux disorder; the surgery is minimally invasive, preventing large bone defects, and reducing operation time and cost of surgery.

In the present series, there were no cases of arterial bleeding. All patients underwent surgery with the supratentorial approach and had complete hematoma evacuation. Control CT scans 12 and 24 hours postsurgery revealed no further bleeding or residual hematomas. Our study indicates that the supratentorial approach is as effective as suboccipital craniectomy for the management of SIEDH, and it is not associated with large bone defects and large postoperative wounds.

\section{CONCLUSION}

Our study demonstrates that the supratentorial approach to craniectomy can effectively eliminate SIEDH. It not only leads to satisfactory hematoma evacuation, but is also a minimally invasive surgery, avoiding large bone defects and complex bone fixes, and reducing the operation time and cost of surgery.

\section{REFERENCES}

1. Asanin B: Traumatic epidural hematomas in posterior cranial fossa. Acta Clin Croat 48: 27-30, 2009

2. Avella D, Servadei F, Scerrati M, Tomei G, Brambilla G, Massaro F: Traumatic acute subdural haematomas of the posterior fossa: Clinicoradiological analysis of 24 patients. Acta Neurochir (Wien) 145: 1037-44, 2003

3. Bozbuga M, Izgi N, Polat G, Gurel I: Posterior fossa epidural hematomas: Observations on a series of 73 cases. Neurosurg Rev 22:34-40, 1999

4. Berker M, Cataltepe O, Ozcan OE: Traumatic epidural haematoma of the posterior fossa in childhood: 16 new cases and a review of the literature. Br J Neurosurg 17: 226-229, 2003

5. Bor-Seng-Shu E, Aguiar PH, de Almeida Leme RJ, Mandel M, Andrade AF, Marino R Jr: Epidural hematomas of the posterior cranial fossa. Neurosurg Focus 16:116-121, 2004

6. Balik V, Lehto H, Hoza D, Sulla I, Hernesniemi J: Posterior fossa extradural haematomas. Cen Eur Neurosurg 71:167-172, 2010

7. Costa Clara JM, Claramunt E, Ley L, Lafuente J: Traumatic extradural hematomas of the posterior fossa in children. Childs Nerv Syst 12:145-148, 1996

8. Cervoni L, Rocchi G, Salvati M, Celli P, Maleci A: Extradural haematoma of posterior cranial fossa. J Neurosurg Sci 37: 47-51, 1993

9. Cheung PS, Lam JM, Yeung JH, Graham CA, Rainer TH: Outcome of traumatic extradural haematoma in Hong Kong. Injury 38:76-80, 2007

10. Dirim BV, Oruk C, Erdogan N, Gelal F, Uluc E: Traumatic posterior fossa hematomas. Diagn Interv Radiol 11:14-18, 2005

11. Gelabert M, Prieto A, Allut AG: Acute bilateral extradural haematoma of the posterior cranial fossa. $\mathrm{Br} J$ Neurosurg 11:573-575, 1997

12. Kabre A, Alliez JR, Kaya JM, Bou Harb G, Reynier Y, Alliez B: Extradural hematoma of the posterior fossa. Neurochirurgie 47:105-110, 2001

13. Lui TN, Lee ST, Chang CN, Cheng WC: Epidural hematomas in the posterior cranial fossa. J Trauma 34: 211-215, 1993

14. Roka YB, Kumar P, Bista P, Sharma GR, Adhikari P: Traumatic posterior fossa extradural haematoma. JNMA J Nepal Med Assoc 47:174-178, 2008

15. Rivano, Borzone CM, Altomonte M, Capuzzo T: Traumatic posterior fossa extradural hematomas. Neurochirurgia (Stuttg) 35:43-47, 1992

16. Wang EC, Lim AY, Yeo TT: Traumatic posterior fossa extradural haematomas (PFEDH). Singapore Med J 39:107-111, 1998

17. Yilmazlar S, Kocaeli H, Dogan S, Abas F, Aksoy K, Korfali $E$ : Traumatic epidural haematomas of nonarterial origin: analysis of 30 consecutive cases. Acta Neurochir (Wien)147: 1241-1248, 2005 